\title{
International Summit Consensus Statement: Intellectual Disability Inclusion in National Dementia Plans
}

Karen Watchman, $\mathrm{PhD}^{1}$, Matthew P. Janicki, $\mathrm{PhD}^{2}$, Michael Splaine, MA ${ }^{3}$, Frode K. Larsen ${ }^{4}$, Tiziano Gomiero, $\mathrm{PhD}^{5}$ and Ronald Lucchino, $\mathrm{PhD}^{6}$

${ }^{1}$ University of Stirling, Scotland, UK

${ }^{2}$ University of Illinois at Chicago, USA

${ }^{3}$ Splaine Consulting, Columbia, Maryland USA

${ }^{4}$ Norwegian National Advisory Unit on Ageing and Health, Oslo, Norway

${ }^{5}$ ANFFAS Trentino Onlus, Trento, Italy

${ }^{6}$ Utica College, Sarasota, Florida USA

Accepted for publication in American Journal of Alzheimer's Disease \& Other Dementias by SAGE.

Corresponding Author:

Karen Watchman, PhD.

Senior Lecturer in Ageing, Frailty and Dementia

Faculty of Health Sciences and Sport

University of Stirling, Stirling, FK9 4LA, Scotland, UK

Email: Karen.Watchman@stir.ac.uk

Tel: +44 1786466387 


\begin{abstract}
The WHO has called for the development and adoption of national plans or strategies to guide public policy and set goals for services, supports, and research related to dementia. It called for distinct populations to be included within national plans, including adults with intellectual disability (ID). Inclusion of this group is important as having Down syndrome is a significant risk factor for early-onset dementia. Adults with other ID may have specific needs for dementia-related care that, if unmet, can lead to diminished quality of old age. An International Summit on Intellectual Disability and Dementia in Scotland reviewed the inclusion of ID in national plans recommending that inclusion goes beyond just description and relevance of ID. Reviews of national plans and reports on dementia show minimal consideration of ID and the challenges that their carers face. The Summit recommended that persons with ID, as well as family carers, should be included in consultation processes and greater advocacy is required from national organisations on behalf of families, with need for an infrastructure in health and social care that supports quality care for dementia.
\end{abstract}

Key words: dementia, Down syndrome, intellectual disability, national plans, strategies, Running head: National dementia plans 


\section{Introduction}

Many nations are experiencing a significant increase in the proportion of ageing persons in their populations along with corresponding increases in age-related conditions. This includes dementia stemming from neurodegenerative conditions such as Alzheimer's disease. ${ }^{1}$ Such demographic shifts and disease contingencies apply also to ageing adults with lifelong intellectual disability. $\left.{ }_{1}\right)$ Overall, some 24 million adults are projected to be affected by dementia worldwide; of these there are at least 225,000 older adults with ID, with $10-20 \%$ having Down's syndrome. Due to the high risk for Alzheimer's disease, adults with Down's syndrome represent a large segment of the intellectual disability population with early-onset dementia. ${ }^{3,4}$ An International Summit in Scotland $\left.{ }^{(}\right)$considered a range of critical and emerging issues in the field of intellectual disability and dementia, including areas of convergence and divergence, some of which are addressed elsewhere. ${ }^{5,6}$ In this paper, we specifically explore strategies for advocating and working toward including people with ID within national dementia strategies and plans.

\section{The World Health Organization's report on Dementia: A Public Health Priority ${ }^{1}$}

called for the development and adoption of national dementia plans or strategies to guide

\footnotetext{
1The WHO defines an intellectual disability as a significantly reduced ability to understand new or complex information and to learn and apply new skills (impaired intelligence). This results in a reduced ability to cope independently (impaired social functioning), and begins before adulthood, with a lasting effect on development. The disability depends not only on the individual's health conditions or impairments but also and crucially on the extent to which environmental factors support the individual's full participation and inclusion in society.

2 This consensus statement was developed as an output from the International Summit on Intellectual Disability and Dementia held in Glasgow, Scotland, 13-14 October 2016, hosted by the University of Stirling and University of the West of Scotland. Collaborating sponsors included the National Task Group on Intellectual Disabilities and Dementia Practices (NTG) in the United States and the University of Illinois at Chicago. The Summit was composed of 32 individuals and representatives of international and national organizations across 12 countries with a stake in issues related to adults with intellectual disability affected by dementia. The contents of this statement were partially developed under a grant from the United States Department of Health and Human Services, Administration for Community Living (ACL), National Institute on Disability, Independent Living, and Rehabilitation Research (NIDILRR) Grant \# 90RT5020-03-00. However, those contents do not necessarily represent the policy of the US Department of Health and Human Services, nor the endorsement by the US Federal Government. The opinions expressed represent those of the Summit participants and of the NTG.
} 
public policy and set development goals for services, supports, advocacy, and research related to dementia. Whilst there are thirty such plans in existence or in development across Europe, the total figure of only eighty-one worldwide suggests many countries have not yet adopted their first plan. ${ }^{7}$ Where these national plans are in place they address diverse issues such as encouraging research into the causes and eventual prevention of dementia, establishing early diagnosis and treatment programmes, undertaking surveillance efforts, promoting the support of treatment strategies and managing supports for caregivers, setting up public education programmes, integrating pathways of care and enhancing the capabilities of workers to care for and support adults affected by dementia. ${ }^{8,9}$ In fact, many national dementia plans additionally focus on the social care aspects of helping people with dementia, including promoting the importance of individuals remaining at home for as long as possible; making more services dementia-capable, supporting carers to delay the move of individuals with dementia to long-term care and giving individuals living with dementia as much control over their care as possible. However, challenges remain, often due to increasing cognitive impairment (for example, in relation to having the capacity to make informed choices), equating service provision with need, promoting early diagnosis, coordinating services at the local level, and making long-term care environments as home-like as possible. ${ }^{10}$

The World Health Organisation's report also called upon countries to address the needs of diverse groups within the scope of these national dementia plans; such as minority ethnic groups, persons with early-onset dementia, and adults with lifelong disabilities (such as intellectual disability). ${ }^{1}$ Within this context, Alzheimer's and other dementia associations around the world have been advocating for the adoption of comprehensive national and subnational Alzheimer/dementia plans as a means to gain attention and focus on the social, health, and economic issue that dementia is becoming and to define solutions and mobilize resources. These plans also call attention to smaller subsets of the dementia community and 
have been a vehicle for persons affected by dementia and their supporters to speak out about living with dementia.

One such subset is adults with lifelong disabilities, such as intellectual disability. Inclusion of this population in national dementia plans is imperative as research shows that adults with an intellectual disability generally experience dementia at a similar or higher rate than do other adults. For the most part their primary carers are home-based parents and other relatives who have been carers over extended periods. Further, as having Down syndrome is a major risk factor for Alzheimer's disease; many such adults are at risk for early-onset dementia leading to a shortened life and diminished quality of old age. ${ }^{11,12}$ Some studies suggest that some $50-70 \%$ of adults with Down will be affected by dementia by age of 60. ${ }^{13,14,15}$ For other types of intellectual disability, studies point to prevalence rates for this population as equivalent or greater than the general population. Both Janicki and Dalton ${ }^{16,}$ and Zigman et al. ${ }^{17}$ using large populations reported prevalence in line with the general population. Other reports, such Strydom et al. ${ }^{15}$ and Cooper ${ }^{18}$ noted higher prevalence in limited populations of adults with ID other than Down syndrome. The WHO recognised this phenomenon and included people with ID among those who should be specifically addressed in national dementia plans. ${ }^{1}$

Given the above findings, the convergence of interests among dementia services and advocacy planning bodies, public health authorities, intellectual disability services and advocacy organisations should work to assure the inclusion of this focal area within such national strategies and plans. These interests converge around meeting mental and physical health and social care needs, as well as providing for long-term care when a neuropathological disease becomes prominent. Where they might diverge is with respect to service specialisation, with special housing and family supports having prominence within intellectual disability services in older age. 


\section{National dementia strategies and intellectual disability}

\section{Defining service needs}

The core principle guiding services for adults with ID is that any service should be aimed at meeting each individual's needs - this principle is summarised in the concept of 'person-centred planning' which has been widely promoted as an effective framework for service delivery. ${ }^{19}$ Decision-making should be focused on each individual's strengths, capabilities, skills, and wishes and each individual's family, relatives and closest friends should be engaged with the person in all decisions with the aim of helping the person remain in his or her chosen home and community. These notions are encapsulated in the Edinburgh Principles, which are seven statements identifying a foundation for the design and support of services to people with ID affected by dementia, and their carers. ${ }^{20}$

Summit participants recognised that some of the services needed to help adults with ID are the same as are needed by other adults with dementia. The underlying assumption is that as dementia progresses it lessens an individual's ability to be left alone - thus, living without supervision is progressively less of an option. The core need is provision of safe adapted housing, continued engagement, and safety monitoring, as well as assistance with personal care, the nature of which will be dependent upon the degree of dysfunction experienced by the adult. Supports related to dementia care fall into several categories ${ }^{21}$, typically following a timeline towards decline. ${ }^{22,23,24}$ Generally, this starts with pre- and peri-diagnostics and involves the screening for and early detection of cognitive problems potentially transitioning into dementia; included here are assessment and diagnostic services, and related follow-along services that track the progression of the dementia. It is followed by post-diagnostic supports, such as non-pharmacological interventions, personal care, day services and diversion programs, and community-based housing (i.e., group homes). In 
parallel are supports designed to address health status and comorbidities, dental, mental and physical health care, and related needs. ${ }^{25}$ An ancillary support area also addresses aid for the carers of the person, including caregiver respite, enrolment in support groups, advice for advanced planning for alternative care, and advice on end-of-life supports. Many of the above requirements for care and support are a given within the intellectual disability system;

whereas, these are not implicit concerns in the general population until after the onset of dementia. Our focus here is to highlight the importance of this distinction and of including this population in the development of future plans and strategies, with some pertinent sources of information to support this included in Table 1.

\begin{tabular}{|c|c|c|}
\hline Function & Purpose/outcome & Possible Sourcing \\
\hline $\begin{array}{l}\text { Determining the extent of } \\
\text { service population at-risk or } \\
\text { diagnosed with dementia }\end{array}$ & $\begin{array}{l}\text { Gaining understanding of the } \\
\text { extent and nature of the } \\
\text { population of adults with } \\
\text { intellectual disability with } \\
\text { potential risk for dementia }\end{array}$ & $\begin{array}{l}\text { University or government } \\
\text { department/ministry } \\
\text { commissioned studies, census } \\
\text { data, local service population } \\
\text { registries }\end{array}$ \\
\hline $\begin{array}{l}\text { Designating supports for } \\
\text { dementia-related impairments } \\
\text { related to housing, clinical } \\
\text { support teams, training of staff, } \\
\text { assessment and diagnostics }\end{array}$ & $\begin{array}{l}\text { Expanding options for } \\
\text { personalized supports and } \\
\text { services for adults with } \\
\text { intellectual disability affected by } \\
\text { or at risk of dementia }\end{array}$ & $\begin{array}{l}\text { Non-governmental and third } \\
\text { sector organizations, providers of } \\
\text { services, parent and family-based } \\
\text { associations, medical societies } \\
\text { and other professional } \\
\text { associations }\end{array}$ \\
\hline $\begin{array}{l}\text { Resourcing help for families, } \\
\text { such as aiding care-at-home, } \\
\text { alternative care planning, and } \\
\text { supports for carers }\end{array}$ & $\begin{array}{l}\text { Expanding options for } \\
\text { personalized supports and } \\
\text { services for carers of adults with } \\
\text { intellectual disability affected by } \\
\text { dementia }\end{array}$ & $\begin{array}{l}\text { Needs assessments of families, } \\
\text { consultation with family-based } \\
\text { disability associations, non- } \\
\text { governmental and third sector } \\
\text { organizations, dementia advocacy } \\
\text { organizations }\end{array}$ \\
\hline $\begin{array}{l}\text { Financing and budgeting for a } \\
\text { planned distribution of resources }\end{array}$ & Funding for supports and services & $\begin{array}{l}\text { Government department/ } \\
\text { ministry resources, legislative } \\
\text { reports, university studies, } \\
\text { national budget overseers }\end{array}$ \\
\hline $\begin{array}{l}\text { Workforce enhancement via } \\
\text { formalized education and } \\
\text { training efforts }\end{array}$ & $\begin{array}{l}\text { Increasing capacity and } \\
\text { capabilities of direct service } \\
\text { personnel, clinicians, and } \\
\text { administrators to provide quality } \\
\text { dementia care }\end{array}$ & $\begin{array}{l}\text { University centers on } \\
\text { aging/gerontology or disability, } \\
\text { provider organizations, unions } \\
\text { and worker associations, training } \\
\text { organizations }\end{array}$ \\
\hline
\end{tabular}




\begin{tabular}{|l|l|l|}
\hline $\begin{array}{l}\text { Integrating special-focus } \\
\text { dementia services with national } \\
\text { health insurance schemes }\end{array}$ & $\begin{array}{l}\text { Assuring inclusion of services and } \\
\text { payments for services for } \\
\text { dementia care for persons with } \\
\text { intellectual disability }\end{array}$ & $\begin{array}{l}\text { Insurance providers, } \\
\text { governmental health policy } \\
\text { officials, disability and dementia } \\
\text { advocacy organizations }\end{array}$ \\
\hline $\begin{array}{l}\text { Assuring quality in care, in } \\
\text { perceived quality of life, and in } \\
\text { services outcomes }\end{array}$ & $\begin{array}{l}\text { Improving quality within services } \\
\text { provision and increase quality of } \\
\text { life for adults with intellectual } \\
\text { disability affected by dementia }\end{array}$ & $\begin{array}{l}\text { Quality review organizations, non- } \\
\text { governmental and third sector } \\
\text { organizations, disability and } \\
\text { dementia advocacy organizations, } \\
\text { national provider organizations }\end{array}$ \\
\hline
\end{tabular}

As highlighted in Table 1, the Summit notes that to put these service needs in a planning perspective for national plan inclusion would require addressing the following: determining the extent of the number of people with ID, especially Down syndrome, at-risk or diagnosed with dementia, defining their needs, and identifying what gaps in services exist. Elaborations are needed on designating supports for dementia-related impairments, dementia-capable housing, training and making available clinical support teams, providing a program of training for staff carers, defining resources for assessment and diagnostics, identifying health and other clinical resources, and sourcing help for families, such as aid with care at home, alternative care planning, financial aid, and other carer supports.

The impact of intellectual disability.

Although the absolute numbers of adults with ID nationally or locally may not be great, their numbers still poses a significant challenge due to the greater impact on long-term caregiving families and specialized public services. In England, for example about 0.15$0.25 \%$ of the population are older adults with ID but they consume up to $5 \%$ of the total public personal care budget. ${ }^{26}$ Many older adults with ID live in the family home with parents who are themselves older, or with a sibling. Others are supported by social care providers either in their own home, or shared accommodation supported by staff who are often the primary carers and who may need information and specialized input. Often the onus falls on organisations, such as national Alzheimer's societies, to respond to inquiries, 
yet many by their own admission are not equipped or informed enough to do so. ${ }^{27}$ Older persons' services typically have a fixed requirement of 60 or 65 years of age for access to their services, leaving persons with ID who may have an earlier age of onset (particularly those with Down's syndrome), and often their families, with unmet needs.

\section{Linking to services}

A key consideration is how national organisations devoted to advocacy on behalf of people affected by Alzheimer's disease and related dementias address the needs of people with ID and dementia, and the needs of their carers, whether paid staff or family members, whose main difference, in many instances, is a lifelong dependency status. One survey ${ }^{28}$ of Alzheimer's Disease International's (ADI) 77 national affiliates organisations revealed that there was resistance in their constituents to bridging the dementia and disability agenda. This was evident from the perception of their government's lack of financial support, resistance from within their organisation's administration, or a belief that their services were inappropriate to the needs of people with intellectual disabilities and dementia. Such difficulties were amplified by a lack of understanding of key issues affecting people with ID and their families; by not having an established linkage with a national Down syndrome group; low awareness of risk of people with Down syndrome developing dementia; lack of support to offer service to this group (although typically a willingness existed to co-operate with parents' association of persons with ID); and lack of appreciation of the longevity of people with ID. These findings showed that there was disconnect between the daily demands on the Alzheimer's organisations for more services and the low awareness on the part of governmental agencies or ministries about people with ID or their families. Given that most of the organisations reported a very low rate of involvement or support from public authorities, it would appear that inclusion in national plans would be a challenge; yet, such inclusion would be an optimal way to raise awareness, commit resources, include adults with 
ID within general dementia services, and support both formal (paid) and informal (family) carers.

Some countries have begun to include consideration of intellectual disability within national or regional strategies and plans. Splaine Consulting conducted a survey ${ }^{27}$ of seventynine national and subnational dementia plans and found that approximately $37 \%$ mentioned adults with intellectual/learning $\left({ }_{3}\right)$ and/or developmental disabilities, with variation in how this was included. For example, some presented information about ID and dementia, whilst others presented actions that are taking place. It should be noted that although some countries have yet to develop a national plan or strategy, a small number are onto their second, or in the case of Scotland, their third. Attention should be paid to changes in second and subsequent plans that recognise this development with an increased recognition, albeit in a limited manner, of the needs of marginalized populations in relation to dementia care. For example, in Norway's first dementia plan, Dementia 2015, people with ID were omitted entirely, yet in the second, Dementia 2020, there is a distinct section related to intellectual disability with the clear recommendation that support models identified in national dementia plans should also be adapted to people with ID. ${ }^{29}$ In Scotland, the first dementia plan ${ }^{30}-$ Scotland's National Dementia Strategy - made reference to the link between Down syndrome and dementia, while the second ${ }^{31}$ - Scotland's National Dementia strategy 2013-2016 - made a specific commitment to seek further information that will inform the third strategy due in 2017. In the USA, the annual updates to the National Plan to Address Alzheimer's Disease ${ }^{32}$ which has a timeline of 2025, progressively have increased mention of intellectual disability since the Plan's first iteration in 2012. ${ }^{33}$ This is a productive progression, perhaps indicative of increased recognition not only of the incidence and prevalence, but of the supports available

\footnotetext{
3 The term 'learning disability' is prevalent in the UK; it is synonymous with the universally used term 'intellectual disability'.
} 
recognising the unique characteristics of this population. Such inclusion in national plans serves to make the document immediately relevant for staff of intellectual organizations as do any recommendations for dementia-related training and awareness raising.

\section{Plan information}

Summit attendees considered what aspects needed to be considered when addressing intellectual disability in national strategies or plans. One would be demographics; it is useful report the number or percentage of the population that this group represents. If epidemiological data are absent, then an estimate of the persons potentially affected can be ascertained by identifying the number of adults aged 60 and older with ID, and assume that at minimum six percent of this group may be affected by dementia. However, it is also necessary to factor in an estimate of those adults age 45 to 59 (due to health implications associated with premature aging and early-onset dementia). Second, derive a figure for home-based caregivers. To do this, estimate, or ascertain from government departments, the numbers of families throughout the country who may be home-based carers of older adults with ID, and in particular those with Down syndrome, so as to identify the risk population for home-based support services. Third, determine the number of persons currently being supported. To do this, ascertain the numbers of older adults in formal services within the country and derive an estimation of the risk for dementia - so as to plan for out-of-home based care. The assumption is that demand for out-of-home care may increase as the primary carers age. In many instances this be the result of the additional stress experienced by families where the primary carer may be an older parent who is experiencing health or cognitive changes.

The degree of specificity of inclusion of dementia-related services for persons with ID in national plans may be driven by the availability of mandated services for persons with ID 
within a country. Specialized dementia-capable services adapted to persons with ID are already in prevalent use in those countries with established formal life-span support schemes for persons with lifelong special needs. ${ }^{33}$ In these instances, plan consideration may be on recognizing the utility of such services and advocating for their expansion. In countries with informal and less established or undeveloped services for persons with ID, adaptation of foundational models applicable to dementia care that may be in use with the general population may be appropriate. In these instances, the plan consideration may be on advocating for adapting such generic services to the care of persons with ID. Such foundational process models widely used in generic dementia services, and which also may be appropriate for use with persons with ID, typically include those that focus on personcentred care. Examples of these include, the VIPS framework model of person-centred care $^{34}$; dementia care mapping ${ }^{35}$; and the Marte Meo method with application to dementia. ${ }^{36}$ There are also specialized delivery models that can apply to both persons with ID and to the general population. Such specialty delivery models already in prevalent use within intellectual disability services include use of small, community-centred group homes (which offer an alternative to institutional congregate care), and enrolment in day support services, which provide a nurturing environment for persons with dementia, and respite for carers. ${ }^{33}$

Another plan consideration would be directed toward raising public awareness. This can work on two levels. The first is a focus on the general public and the second on the aging and disability-related services' workforce. Raising general awareness within the public can further advocacy goals and gain support from voters for legislation enhancing services or the channelling of public funds. With respect to the personnel employed in dementia-related support functions, workforce capacity enhancement should target all levels of workers, including administrators and clinicians, so that they become more proficient in understanding and identifying dementia. Workforce enhancement should also include gaining familiarity 
with dementia-capable care and environments. ${ }^{37}$ Including this aspect in plans can further the goal to enable early identification of adults with ID showing symptoms so as to facilitate engagement in the diagnostic process, and enable them and their carers to begin to plan for additional care and health intervention as appropriate as dementia progresses. ${ }^{38}$ Equally important is ensuring that the need for medical screening, assessment, and diagnostic resources are stated in the plan, and then pursued in order to identify dementia in adults with ID. This can serve several purposes, one is to identify the nature of the dementia (and its etiology) and another is to conduct a differential diagnosis and eliminate other neuropathological causes for behaviour change (such as depression, adverse drug reactions, or thyroid conditions). Additional benefits include having a workforce with a stronger grounding in dementia and an understanding of the services and approaches that work best when supporting persons with ID affected by dementia. Lastly, focal areas in the plan should address practices enhancing the quality of life of adults with ID affected be dementia. ${ }^{39,40}$

Further plan considerations can include the bridging of care supports within the intellectual disability system with those of providers whose primary goal is to serve persons with dementia. Nakanishi and Nakanishi ${ }^{40}$ noted the importance of cooperation among 'silos' as a feature to be encouraged in national plan efforts. This could involve inclusion within efforts to plan housing, homecare supports, medical reviews and treatment, palliative care and hospice teams, and end-of-life care activities. The plan development may also consider how to form and support voluntary advocacy groups, who can help input into the plan and serve as a 'watchman' or 'overseer' over the delivery of public services which may be a first step towards the voice of people with ID being heard in focus groups for new policy development. ${ }^{33}$ Lastly, the plan should incorporate the requirement to include intellectual disability in any research related to dementia being undertaken, whether basic or remedial 
(i.e., medical or social). Also, any research focusing in prevention should give due consideration to intellectual disability and include persons with ID as subjects.

In summary, the Summit proposes that national dementia strategies or plans minimally include, but preferably go beyond, passive functions, including description and relevance of this group and notations of the higher risk factor recognition. This should extend to proactive functions including: recognition of the need for access to specialised diagnosis resources, maintaining quality of care and quality of life as dementia progresses to advanced stage recognising complexities with recognising end of life, increasing capacity of the workforce via training and education for service providers, support for (unpaid) carers of persons with intellectual disability and dementia, enabling adaptation of existing intellectual disability services to accommodate dementia; proposing reviews of health care schemes and public funding programs, so that intellectual disability providers can receive payments or reimbursements commensurate with costs of dementia care; instituting healthy brain and physical health initiatives (to promote prevention); and undertaking government supported research activities in both the underlying etiological factors and best practices in providing quality care.

\section{Strategies for inclusion in dementia plans}

One consideration is the extent to which persons with dementia are involved in existing national plan development or implementation. Alzheimer Disease International commissioned a study ${ }^{28}$ that looked at 20 extant national plans to ascertain whether persons with dementia in general were involved with plan development, and found that persons with dementia fell into two main categories. They were either included as members on a task force, working group, or committee, or were involved in a public comment period or consultation process; others had no involvement at all. Of the 20 national plans examined, 
they found that only one country stated persons with dementia were included in its working groups, another included two Alzheimer's patient advocates on a national advisory council which helped create and annually updated the national plan, and five countries involved persons with dementia in workshops or consultation/dialogue/ questionnaire processes, or mention that their plan was informed by the views of persons with dementia. The study found that the other 14 countries did not specifically mention the involvement of persons with dementia in the development of their national plans, but that this does not necessarily correlate with no involvement of persons with dementia. The 'take-away' from this analysis is that while not many adults with dementia are involved in the national plan development and oversight process, even less involvement may be of adults with ID or their advocates.

We know of no instances in which persons with ID (who are conceivably at risk of dementia and capable of personal involvement in planning groups) have had a role in the task forces/work groups that have developed national dementia plans; rarely also are their advocates included in their working groups. Thus, public testimony and advocacy by surrogates and concerned government agencies seem to be the sources of influence. Given that we know very little about this, the Summit working group recommends investigating to what extent there is any involvement by adults with ID in dementia plan development groups. Another investigation should examine to what extent national voluntary or third sector organisations are devoting efforts to advocacy on behalf of people with ID affected by dementia. Anecdotally, there seems to have been little pressure from third sector organisations on issues around ageing in general among people with ID. Intellectual disability organisations are more likely to have input into disability-specific policy rather than dementia-related policy despite the known incidence and prevalence. Among intellectual disability organizations, parents are the largest group of members and it seems that most have a primary focus on the challenges their children face when they are younger, with far fewer 
engaged in these organisations when their children are older adults. It may be that when there are few relatives who engage in this type of advocacy, there is also no pressure on the national dementia organisations and governments. ${ }^{33}$ Also, at the time of highest risk for dementia parents may themselves likely be aging, affecting their continued engagement.

A resource for information on the inclusion of people with ID within a national plan is to draw upon other reports or pressure presented by national advocacy organizations. Examples of such national reports/plans are the 'My Thinker's Not Working' document issued by the National Task Group on Intellectual Disabilities and Dementia Practices in the United States $^{42}$ and "Dimentica la Disabilità e Guarda alla Persona", issued by a consortia of organizations in Italy. ${ }^{43}$ Both of these documents provide a wide-ranging analysis of the needs of adults with ID affected by dementia and include goals and plans for the development of services and addressing of needs. $\left.{ }^{(}\right)$Another example is "Dementia and Equality Meeting the Challenge in Scotland", a report that followed Scotland's second National Dementia Strategy 2013-16 identifying 17 national commitments underpinned by a human rights approach. ${ }^{44}$ This strategy highlights five particular population groups with characteristics protected by the Equality Act $2010^{45}$, where challenges might arise in the context of dementia, one of which is intellectual disability. Also, the Norwegian Dementia Plan 2020 recognised the absence of minority groups, including people with intellectual disabilities, and affirmed that all strategies and measures in the plan must be adapted to people with intellectual disabilities. ${ }^{29}$ It does not need to be only a national or local plan that informs inclusion in general dementia plans; the Convention for the Rights of Persons with

\footnotetext{
4 An outcome of the Italian plan effort is that the text of the report is now included on the website of the local government, and can be downloaded as an official appendix to the regional dementia plan. See http://www.trentinosalute.net/Contenuti/Temi/Demenze/Pubblicazioni-dei-soggetti-della-rete
} 
Disabilities $^{46}$ can be drawn upon to infuse consideration of the perspectives of persons with dementia (including those with ID) into the national public policy and planning discourse. ${ }^{47}$

Thus, strategic initiatives may have to be undertaken to actively promote the inclusion of intellectual disability in national plans. These efforts may include any or all of the following: (a) ensuring that adults with ID with knowledge of dementia are invited onto planning groups or working parties providing contributions to national plans and related policy; (b) contributing to issue-briefs and policy letters on dementia and intellectual disability by national or other self-interest groups within the intellectual disability field; (c) requesting inclusion of representatives of national intellectual disability organisations onto national councils, boards, or planning bodies creating or monitoring national dementia plans; (d) advocating and raising awareness among governmental officials and bodies of the public policy issues related to dementia and intellectual disability; (e) advising on how dementiacapable care environments can be further adapted to meet the particular needs of adults with ID; and (f) creating public awareness by assisting the press and other media to develop and present human interest stories about carers and persons with ID affected by dementia.

\section{Recommendations}

Noting the issues and problems related to gaining attention for adults with intellectual disability affected by dementia, the Summit recommended that:

- Advocates and self-advocates, including intellectual disability or Down syndrome specific organisations, mobilise to make their issues known to authorities responsible for the development, or redevelopment/update of national dementia plans

- Forums, meetings, and consultations held in advance of national plans being develop or modified should ensure appropriate representation; these should 
include alternate and accessible methods of communication as required to ensure inclusion of people with intellectual disability and families

- Government representatives be drawn into the process and requested to provide demographic, services, and financial data related to intellectual disability for use in the plan

- Discussions be held at a policy level to determine what laws or existing policies may need to be instituted or altered/updated to facilitate the inclusion of intellectual disability in national dementia strategies or plans

- Involve self-advocates, or persons authorised to speak on behalf of adults with an intellectual disability, in the development or review of documents produced related to a national dementia strategy and make available the documents in accessible formats

\section{Summary}

Governments have had a major role in providing for the health, welfare, economic, and social stability for persons with ID. Over the past 60 years, the interpretation of this role has changed considerably, from a focus on a responsibility for remedial and custodial care to one on various supports, social inclusion, and autonomy. With increased longevity, adults with ID, like other persons, now face the prospect of having a neuropathology in old age. ${ }^{48}$ This risk is especially acute for persons with Down syndrome. This means there is a need for inclusion of intellectual disability issues in national dementia planning. To effect inclusion, active advocacy needs to be undertaken to involve individuals and groups representing people with intellectual disabilities on planning bodies and those constructing national plans.

The Summit proposes that inclusive and thoughtful planning on dementia must include people with intellectual disability; recognised by the WHO as a "group having 
additional needs". In addition to the topics noted above, plans also should designate a consistent policy home for persons dually affected, accurate census/surveillance of the numbers of affected persons, and possible policy changes to empower the carers and services' staff in becoming advocates in address barriers to health care ${ }^{38}$. To make this happen, it is incumbent on intellectual disability organisations to prepare background material, personal stories, and rationales for inclusion. This is in addition to working with policy officers to raise awareness and promote inclusion of their concerns and needs in national dementia service delivery efforts and national and regional plans.

Declaration of Conflicting Interests The authors declared no potential conflicts of interest with respect to the research, authorship, and/or publication of this article.

Funding The authors disclosed receipt of the following financial support for the research, authorship, and/or publication of this article: The contents of this statement were partially developed under a grant from the United States Department of Health and Human Services, Administration for Community Living (ACL), National Institute on Disability, Independent Living, and Rehabilitation Research (NIDILRR) Grant \# 90RT5020-03-00. Additional support was provided by grants from RS MacDonald Charitable Trust, Edinburgh; Alzheimer Scotland, and the Scottish Government.

\section{References}


1. WHO. Dementia: A Public Health Priority. Geneva, Switzerland: World Health Organization and Alzheimer's Disease International; 2012.

2. WHO. Definition: intellectual disability. http://www.euro.who.int/en/healthtopics/noncommunicable-diseases/mental-health/news/news/2010/15/childrens-right-tofamily-life/definition-intellectual-disability. Published 2017.

3. Coppus AMW. People with intellectual disability: What do we know about adulthood and life expectancy? Dev Disabil Res Rev. 2013;18:6-16.

4. Ballard C, Mobley W, Hardy J, Williams G, Corbett A. Dementia in Down's syndrome. Lancet Neurol. 2016;15(6):622-636.

5. McCallion P, Hogan M, Santos FH, McCarron M, Service K, Stemp, S, Keller, S, Fortea, J, Bishop, K, Watchman K, Janicki MP and the Working Group of the International Summit on Intellectual Disability and Dementia. Consensus statement of the international summit on intellectual disability and dementia related to end-of-life care in advanced dementia. J Appl Res Intellect Disabil. In press

6. Janicki MP, McCallion P, Splaine M, Santos FH, Keller SM, Watchman K. Consensus statement of the international summit on intellectual disability and dementia related to nomenclature. Intellect Dev Disabil. In press

7. Alzheimer Europe National Dementia Strategies. Accessed from http://www.alzheimereurope.org/Policy-in-Practice2/National-Dementia-Strategies Published: 2016

8. Kuriakose JR. Comparison of national dementia plans. Alzheimers Dement. 2015;11(7): Supplement, P598.

9. Wortmann M. (2013). Importance of national plans for Alzheimer's disease and dementia. Alzheimers Res Ther. 2013;5(5):40.

10. Alzheimer Society of Canada. Rising Tide: The Impact of Dementia on Canadian Society; 2010 .

11. Bush A, Beail N. Risk factors for dementia in people with Down syndrome: issues in assessment and diagnosis. Am J Ment Retard. 2004;109(2):83-97.

12. Prasher V. Alzheimer's Disease and Dementia in Down Syndrome and Intellectual Disabilities. Oxford: Oxford Publishing; 2005.

13. Janicki MP, Dalton AJ, eds. Dementia, Aging, and Intellectual Disabilities: A Handbook. Philadelphia, PA: Brunner-Mazel; 1999.

14. McCarron M, McCallion P, Reilly E, Mulryan N. A prospective 14-year longitudinal follow-up of dementia in persons with Down syndrome. J Intellect Disabil Res. 2014;58(1):61-70.

15. Strydom A, Chan T, King M, Hassiotis A. Livingston G. Incidence of dementia in older adults with intellectual disabilities. Res Dev Disabil. 2013;34(6):1881-1885.

16. Janicki MP, Dalton AJ. Prevalence of dementia and impact on intellectual disability services. Ment Retard. 2000;38:277-289.

17. Zigman WB, Schupf N, Devenny D, Miezejeski C, Ryan R, Urv TK, Schubert R, Silverman W. Incidence and prevalence of dementia in elderly adults with mental retardation without down syndrome. Am J Ment Retard. 2004;109;126-141. 
18. Cooper S-A. High prevalence of dementia among people with learning disabilities not attributable to Down's syndrome. Psychol Med. 1997;27(3);609-616.

19. Alzheimer's Disease International. Dementia and intellectual disabilities. Published 2003. Accessed from: https://www.alz.co.uk/adi/pdf/intellectualdisabilities.pdf 2003.

20. Wilkinson H, Janicki MP, Edinburgh Working Group on Dementia Care Practices (EWGDCP).). The Edinburgh Principles with accompanying guidelines and recommendations. J Intellect Disabil Res. 2002;46(3):279-284.

21. Alzheimer's Society. How dementia progresses. 2017. Accessed from: https://www.alzheimers.org.uk/info/20073/how_dementia_progresses

22. Keller SM, Janicki MP, Esralew, L. Dementia: Screening, evaluation, diagnosis and management. In IL Rubin, J Merrick, DE Greydanus, DR Patel (eds.), Health Care for People with Intellectual and Developmental Disabilities across the Lifespan (pp.1449-1463). Basel: Springer

23. McCarron M, McCallion P, Reilly E, Mulryan N. Responding to the challenges of service development to address dementia needs for people with an intellectual disability and their caregivers. In K Watchman (ed.), Intellectual Disability and Dementia (p.241-269). London: Jessica Kingsley

24. Janicki MP, Dalton AJ. Dementia and public policy considerations. In M Janicki, A Dalton (eds.). Dementia, Aging, and Intellectual Disabilities: A Handbook. (pp 389-414). Philadelphia: Taylor and Francis

25. Starr JM, Walesby KE. Diagnosis and management of dementia in older people. Medicine. 2017;45(1):51-54.

26. Strydom A, Romeo R, Perez-Achiaga N, Livingston G, King M, Knapp M, Hassiotis A. Service use and cost of mental disorder in older adults with intellectual disability. $\mathrm{Br} J$ Psychiatry. 2010;196(2):133-138.

27. Janicki MP, Wilkinson H. Role of Alzheimer's organizations with respect to aiding families of people with Down syndrome. Paper presented at the 25th International Conference of Alzheimer's Disease International, Thessaloniki, Greece, March 13, 2010.

28. Gardner SO. Intellectual and developmental disabilities and dementia in national and sub-national dementia plans. https://www.alz.co.uk/alzheimer-plans/small-papers-onnational-and-sub-national-dementia-plans. Published 2016.

29. Ministry of Health and Care Services. Demensplan 2020: Et mer demensvennlig samfunn [Dementia Plan 2020: A More Dementia-friendly Society]. Publication code: I1170 E. Oslo, Norway: The Norwegian Government Security and Service. https://www.regjeringen.no/no/dokumenter/demensplan-2020/id2465117. Published 2015.

30. Scottish Government. Scotland's National Dementia Strategy. Edinburgh: Scottish Government. http://www.gov.scot/Resource/Doc/324377/0104420.pdf. Published 2010

31. Scottish Government. Scotland's National Dementia strategy 2013-2016 Edinburgh: Scottish Government. http://www.gov.scot/Topics/Health/Services/MentalHealth/Dementia/DementiaStrategy1316. Published 2013.

32. ASPE. National Alzheimer's Project Act. Washington: Department of Health and Human Services. https://aspe.hhs.gov/national-alzheimers-project-act. Published 2012. 
33. Jokinen N, Janicki MP, Keller SM, McCallion P, Force LT, and the National Task Group on Intellectual Disabilities and Dementia Practices. (2013). Guidelines for structuring community care and supports for people with intellectual disabilities affected by dementia. $J$ Policy Pract Intellect Disabil. 2013;10(1):1-24.

33. Janicki MP, Keller SM. Viability of a dementia advocacy effort for adults with intellectual disability: Using a national task group approach. J Policy Pract Intellect Disabil. 2014;11(3):176-191.

34. Brooker D. Person-centred dementia care. London: Jessica Kingsley Publishers. 2007

35. Finnamore T, Lord S. (2007). The use of Dementia Care Mapping in people with a learning disability and dementia. J Intellect Disabil. 2007:11(2):157-165.

36. Aarts M. Marte Meo Grundbog. Harderwijk, The Netherlands: Aarts Productions. 2000

37. Lin SY, Lewis FM. Dementia friendly, dementia capable, and dementia positive: Concepts to prepare for the future. Gerontologist. 2015;55(2):237-244.

38. Watchman K. Intellectual disability and dementia: a guide for families. London: Jessica Kingsley Publishers. 2017

39. De Vreese LP, Uberti M, Mantesso U, De Bastiani E, Weger E, et al. Measuring quality of life in intellectually disabled persons with dementia with the Italian version of the quality of life in late-stage dementia (QUALID) Scale. J Alzheimers Dis. 2012;2:104e.

40. McCarron M, Reilly, E. Supporting persons with intellectual disability and dementia: Quality dementia care standards - A guide to practice. Dublin: Trinity College Dublin. Published 2010.

41. Nakanishi M, Nakashima T. Features of the Japanese national dementia strategy in comparison with international dementia policies: How should a national dementia policy interact with the public health- and social-care systems? Alzheimers Dement. 2014;10:468476.

42. National Task Group on Intellectual Disabilities and Dementia Practice (NTG). 'My thinker's not working': A national strategy for enabling adults with intellectual disabilities affected by dementia to remain in their community and receive quality supports. www.aadmd.org/ntg/thinker. Published 2012.

43. Gomiero T, De Vreese LP. 'Dimentica la disabilità e guarda alla persona': Una strategia nazionale per permettere agli adulti con Disabilità Intellettiva, affetti da Demenza, di rimanere nella propria Comunità, ricevendo sostegni di qualità [Forget disability and look at the person ': A national strategy to enable adults with intellectual disabilities, suffering from dementia, to remain in their community, getting quality support]. Trento, Italy: Anffas Trentino Onlus. Accessed from: www.anffas.tn.it and ww.validazione.eu/dad. Published 2012.

44. NHS Education for Scotland. Dementia and equality - meeting the challenge in Scotland. Edinburgh, Scotland: National Advisory Group on Dementia and Equality. http://www.healthscotland.com/uploads/documents/27797-

Dementia\%20and\%20equality_Aug16_English.pdf. Published 2016.

45. Government Equalities Office. Equality Act 2010: Guidance Available at: https://www.gov.uk/guidance/equality-act-2010-guidance\#overview. Published February 27, 2013. 
46. United Nations. Convention on the Rights of Persons with Disabilities. Accessed from: http://www.un.org/disabilities/convention/conventionfull.shtml. Published 2006.

47. Crowther N. Harnessing the United Nations Convention on the Rights of Persons with Disabilities to improve the lives of persons with dementia: Executive summary. https://www.alz.co.uk/sites/default/files/pdfs/harnessing-crpd-dementia.pdf. Published March 1, 2016.

48. Horvath S, Garagnani P, Bacalini MG, Pirazzini C, Salvioli S, Gentilini D et al. (2015). Accelerated epigenetic aging in Down syndrome. Aging Cell. 2015;14(3):491-495. 